\title{
Finite Element Modelling of Shock-Induced Damages on Ceramic Hip Prostheses
}

\author{
Juliana Uribe, Jérôme Hausselle, Jean Geringer, and Bernard Forest \\ Biomechanics and Biomaterials Department, Center for Health Engineering, UMR CNRS 5146, IFR 143, \\ Ecole Nationale Supérieure des Mines de Saint-Etienne, 158 cours Fauriel, 42023 Saint-Etienne, France \\ Correspondence should be addressed to Juliana Uribe, uribe@emse.fr
}

Received 5 April 2011; Accepted 20 May 2011

Academic Editors: J. Provis and R. Rodríguez

Copyright (๑) 2011 Juliana Uribe et al. This is an open access article distributed under the Creative Commons Attribution License, which permits unrestricted use, distribution, and reproduction in any medium, provided the original work is properly cited.

\begin{abstract}
The aim of this work was to simulate the behaviour of hip prostheses under mechanical shocks. When hip joint is replaced by prosthesis, during the swing phase of the leg, a microseparation between the prosthetic head and the cup could occur. Two different sizes of femoral heads were studied: 28 and $32 \mathrm{~mm}$ diameter, made, respectively, in alumina and zirconia. The shock-induced stress was determined numerically using finite element analysis (FEA), Abaqus software. The influence of inclination, force, material, and microseparation was studied. In addition, an algorithm was developed from a probabilistic model, Todinov's approach, to predict lifetime of head and cup. Simulations showed maximum tensile stresses were reached on the cup's surfaces near to rim. The worst case was the cup-head mounted at $30^{\circ}$. All simulations and tests showed bulk zirconia had a greater resistance to shocks than bulk alumina. The probability of failure could be bigger than 0.9 when a porosity greater than $0.7 \%$ vol. is present in the material. Simulating results showed good agreement with experimental results. The tests and simulations are promising for predicting the lifetime of ceramic prostheses.
\end{abstract}

\section{Introduction}

Ceramics were investigated in orthopaedics since many years because of their good wear-resistance and loading capacity [1-4]. Ceramic-on-ceramic, CoC, bearing surfaces reduce wear compared to metal-on-polymer, MoP, (The polymer is up today UHMWPE: ultra-high molecular weight polyethylene) or ceramic-on-polymer.

Nevertheless, retrieved heads and cups have sometimes shown wear stripes [5-8]. This pattern of wear has been shown to be related to a phenomenon of microseparation, separation between the centers of the head and the cup, during the stance phase, which generates a contact force between the head and the edge of the cup [9]. This shock is believed to fracture the femoral cup, with a developed force up to 9 times the body weight.

Components for total hip replacement are shown in Figure 1.

Clearly, the shock resistance issue requires a better understanding of the biomechanics of gait cycle. Hip joint forces have been estimated indirectly using inverse dynamics and analytical methods or directly measured with implanted transducers. In general, the force at the hip joint reaches an initial peak in early stance phase and a second peak in late stance phase. This pattern was described in the initial work of Paul [11] and Paul and McGrouther [12]. While the majority of the modelling work has been conducted on normal subjects, Andriacchi and Hurwitz have also conducted a study on few subjects following total hip replacement [13]. However, there is a lack of studies describing how these forces generate stresses on the femoral components and how it can lead to fracture of either one of the components.

Because of the increase of life expectancy, new materials or designs are needed, with a significantly improved lifetime and better mechanical properties. The goal of this study was to develop a model combining finite element analysis and crack growth simulation. The influence of several parameters was then assessed to determine the most significant parameter in relation with shock resistance.

\section{Materials and Methods}

2.1. Materials Properties and Designs. The degradation of two types of materials, alumina and zirconia, Table 1, usually 


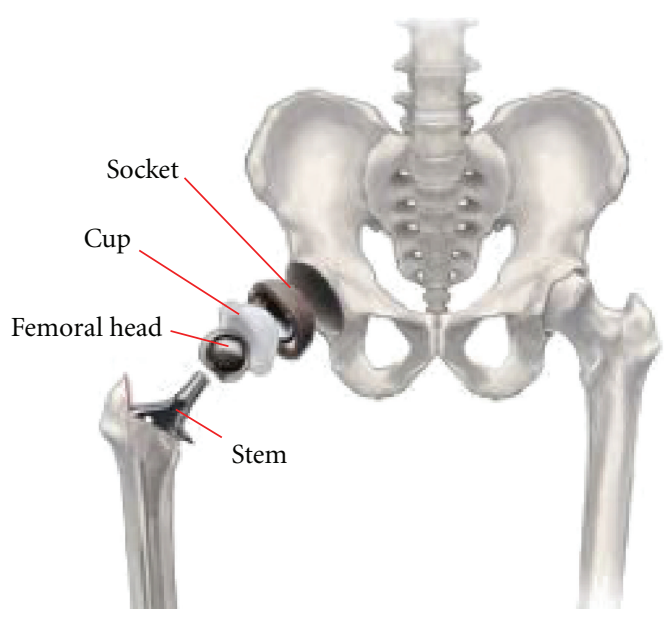

FIGURE 1: Scheme hip articulation [10].

TAble 1: Physical and mechanical properties of alumina and zirconia.

\begin{tabular}{lccc}
\hline & Density $\left(\mathrm{g} / \mathrm{cm}^{3}\right)$ & Young modulus $(\mathrm{GPa})$ & Poisson's ratio \\
\hline $\mathrm{Al}_{2} \mathrm{O}_{3}$ & 4.00 & 400 & 0.23 \\
$\mathrm{ZrO}_{2}$ & 6.05 & 200 & 0.23 \\
\hline
\end{tabular}

used for femoral heads and cups was simulated using FEA and compared to experimental tests results obtained using a shock machine [14], Figure 2(a). The orientation of heads and cups was set to vary between $30^{\circ}, 60^{\circ}$, and $45^{\circ}$, Figure 2(b). Three heads, $32 \mathrm{~mm}$, made from alumina and three heads of $28 \mathrm{~mm}$ made from zirconia were tested. The cups corresponding to heads, in terms of diameter, were investigated.

2.2. Finite Element Modelling. The FE simulations were implemented using commercial software (ABAQUS 6.8, Dassault Systèmes, 2008).

2.2.1. Hypotheses. Materials were assumed to be perfectly elastic, so no plastic deformation was possible. The modelling was carried out in static conditions.

The shock-induced stress was considered constant. Finally, the friction between head and cup was considered negligible.

2.2.2. Loading and Boundary Conditions. Friction coefficient for contact ceramic/ceramic is the weakest compared to other couples of materials. As the friction behaviour, in terms of finite elements analysis (FEA), is not well known, the sliding movement was not considered in the contact. As the friction coefficient is weak, one might suggest that friction forces are negligible compared to contact forces and friction constant was zero.

However, a particular attention was paid on elastic contact and rebound, mechanical energy restored after a shock. An algorithm was developed using a bouncing ball made from zirconia diameter $32 \mathrm{~mm}$. Head-taper fit and head cup were modeled with the same contact algorithm penalty. This contact with the option "hard contact" allows modelling elastic contacts. This algorithm was developed using a ball made of zirconia which falls from a height of $10 \mathrm{~mm}$ and impact. Coefficient of restitution was then calculated

$$
e=\sqrt{\frac{h_{i+1}}{h_{i}}}
$$

where $h_{i}$ and $h_{i+1}$ are the height before and after bouncing, respectively. This calculation was made for 8 bounces, and the coefficient of restitution was calculates as $e=0.95 \pm 0.03$, and this value suggest the shock is purely elastic.

Even though is possible to input a friction model in Abaqus, the model is unknown. That is why we said that there is not sliding in the contact. Moreover, the cup was constrained in all degree of freedoms to reproduce the shocks device.

In addition, symmetry conditions were imposed on the vertical axis. A load of $9 \mathrm{kN}$ was defined for the contact head cup at the upper rim. Load was applied at the centre of the cone and increased linearly from zero to its maximum value at $11 \mathrm{~ms}$ which are the same conditions that experimental shock tests. Boundary conditions and definition of angles are shown in Figures 3(a) and 3(b).

Angles will be called in following work by words, theta and phi, instead of Greek letters, $\theta$ and $\phi$, because of better printing process with Matlab software.

2.2.3. Meshing. Two different sizes were studied, 28 and $32 \mathrm{~mm}$ in diameter. The first model consisted of a $28 \mathrm{~mm}$ femoral head and a cup, both made of zirconia and a cone made of Ti-6Al-4V. Young's modulus and Poisson's ratio for zirconia were set to $200 \mathrm{GPa}$ and 0.23 , respectively; see Table 1. For titanium alloy, a Young's modulus of $110 \mathrm{GPa}$ and a Poisson's ratio of 0.32 were assigned. The mesh consisted of 4262 nodes in the head, 1927 in the cup and 169 for the cone. Second model consisted of a 32 diameter femoral head and a cup made in alumina. Young's modulus for alumina was $400 \mathrm{GPa}$ and Poisson's ratio 0.23 . Head had 4799 nodes, cup 2534, and 145 for the cone. The shape of the rim was rounded with a radius of $1 \mathrm{~mm}$. Figure 4(a) shows the three dimensional assembly.

Both FEA models were three-dimensional and meshed using tetrahedral solid elements, ideal for meshing complexes geometries. In order to obtain more accurate results, the mesh in the hypothetical contact zones between head and cup were refined, especially at the rim of the cup. Meshing of head, 4799 nodes, cup, 2534 nodes, and cone, 145 nodes, are shown in Figure 4. Materials were considered as hard and rigid. The damping effect would be considered in further investigations.

Several parameters were changed in order to determinate their influence on the stress. These parameters are summarized in Table 2.

2.2.4. Treatment/Post Processing with Matlab. An algorithm implemented in Matlab (Matlab 7.7 The MathWorks Inc.) 


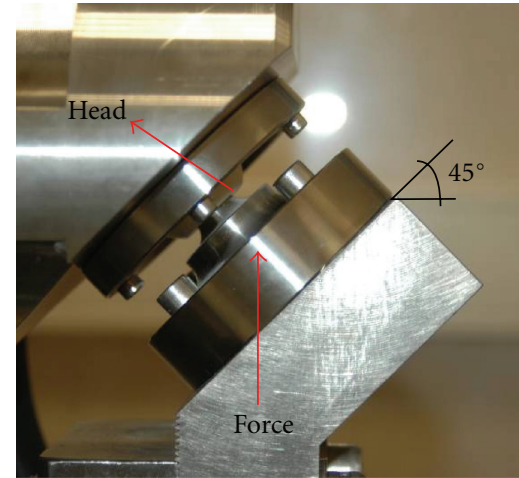

(a)

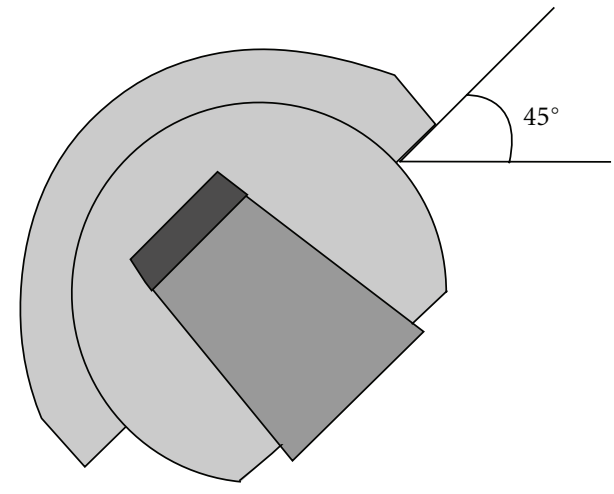

(b)

FIgURE 2: (a) Shock machine. (b) Assembly head and cup at the standard anatomic position.

TABLE 2: Studied parameters: materials, force, microseparation, and inclination.

\begin{tabular}{lcccr}
\hline Parameter & Material & Force & Microseparation $(\mathrm{mm})$ & Inclination \\
\hline Force & Zirconia & $2-9 \mathrm{kN}$ & 1.3 & $45^{\circ}$ \\
Microseparation & Zirconia & $9 \mathrm{kN}$ & $0,0.7,1.0,1.3,1.6,1.9$ & $45^{\circ}$ \\
Inclination & Zirconia & $9 \mathrm{kN}$ & 1.3 & $30^{\circ}, 45^{\circ}, 60^{\circ}$ \\
Material & zirconia alumina & $9 \mathrm{kN}$ & 1.3 & $45^{\circ}$ \\
\hline
\end{tabular}
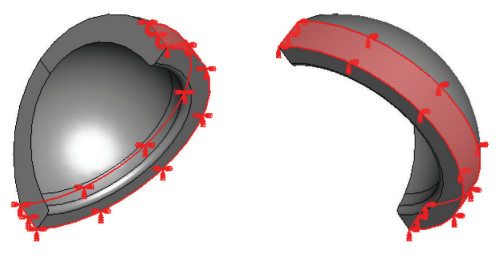

(a)

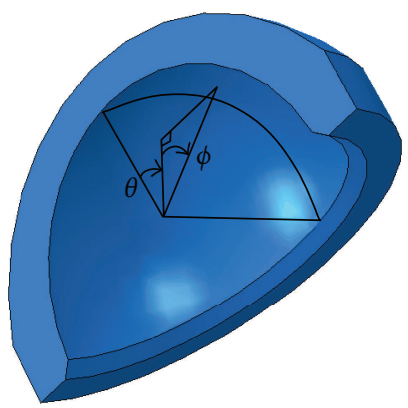

(b)

FIGURE 3: (a) Boundary conditions: degrees of freedom and vertical symmetry. (b) Definition of angles from the center of cup and head.

was used to interpolate stresses on the nodes obtained with ABAQUS. This step is necessary for increasing the number of nodes in order to predict the structure behaviour. For each element, stresses in the nodes were interpolated into a cube; see Figures 5(a) and 5(b).
Thus, stresses on the cup were calculated in about 3 millions of points instead of a few thousands. Number of points was multiplied by 1000 .

\subsection{Algorithm}

2.3.1. General Considerations. Stress intensity factor, $K_{I}$, is defined as

$$
K_{I}=Y \sigma \sqrt{\pi a},
$$

where: $Y$ is a constant which takes into account the geometry and location of the flaw, considered as $1, \sigma$ is the tensile stress, and $a$ is the depth for a crack or radius for a porosity.

Only tensile stresses were considered. Stress is supposed to be maximum and constant during the $11 \mathrm{~ms}$ of the simulation. Therefore, $K_{\max }=K_{I}$, and we have then

$$
v=A K_{I}^{m}
$$

An yttria-doped zirconia has $m=20$, and from experimental curves [15], the constant $A=1.2 * 10^{-18}$ was calculated. Under cyclic solicitations, the ratio between $K_{I 0}$ and $K_{I C}$ is 0.48 [16]. Since $K_{I C}$ is reported to be $5.5 \mathrm{MPa} \sqrt{\mathrm{m}}$ [17], $K_{I 0}=$ 2.7 $\mathrm{MPa} \sqrt{\mathrm{m}}$ was fixed for simulating cyclic solicitations.

For alumina, the same ratio between $K_{I 0}$ and $K_{I C}$ was taken. Hence, $K_{I 0}=2.1 \mathrm{MPa} \sqrt{\mathrm{m}}$ was considered. Coefficients $A$ and $m$ were taken from a $\nu$ versus $K_{I}$ curve for alumina under cyclic solicitations [16]. Coefficients used for alumina and zirconia are summarized in Table 3. Curves used in simulations are shown in Figure 6. 


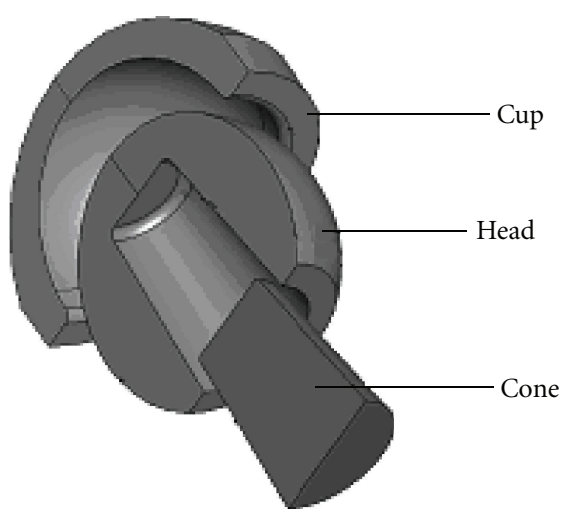

(a)

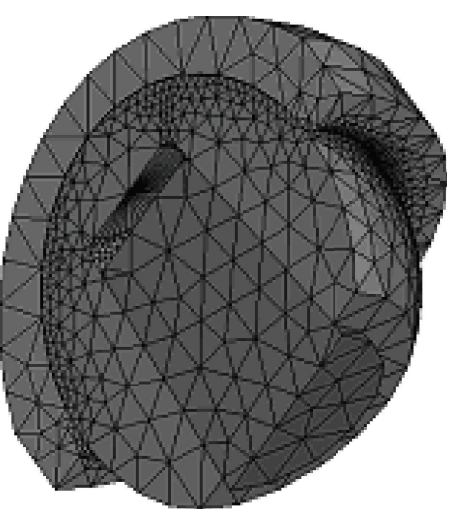

(b)

FIGURE 4: (a) Assembly of the cup, head and cone for the finite element simulation. (b) Refined mesh of the assembly, head with 4800 nodes and cup with 2534 nodes.

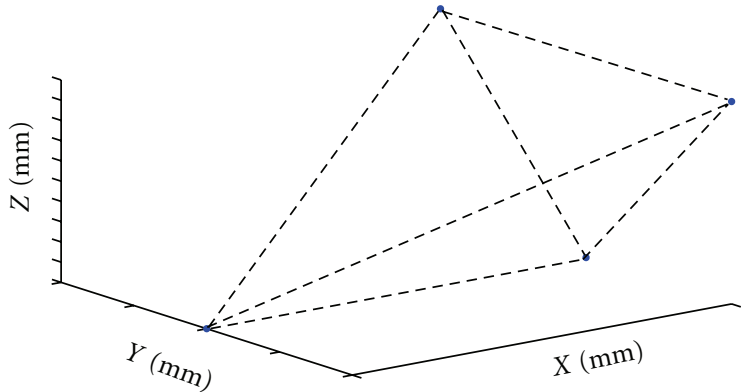

(a)

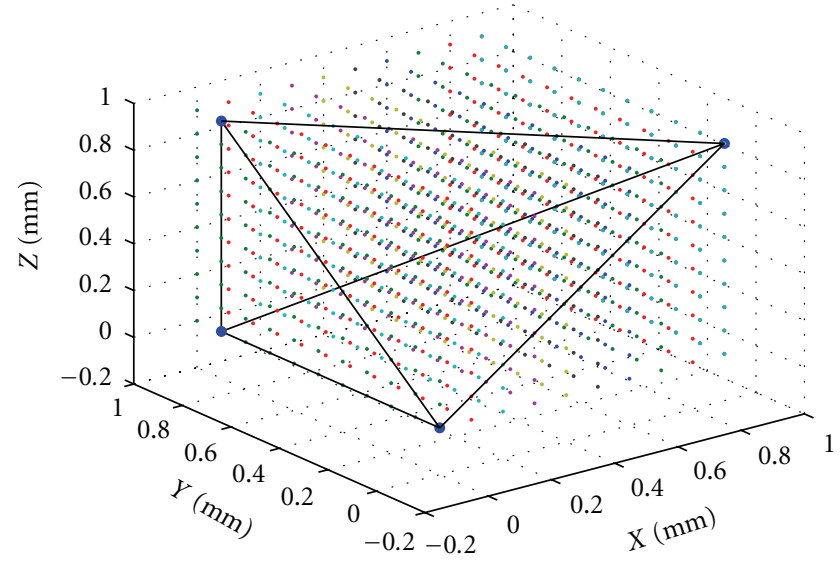

(b)

Figure 5: 3D Interpolation of stresses on the cup. (a) A finite element. (b) Interpolation cube including the element.

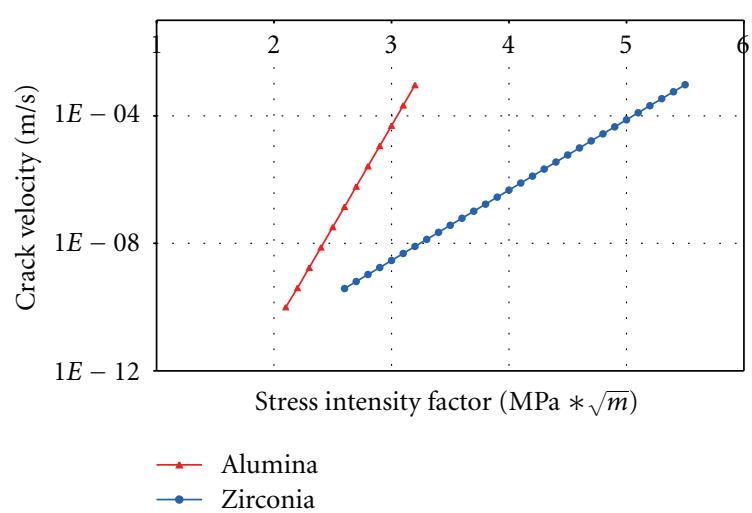

FIGURE 6: Curves $v$ versus $K_{I}$ used for alumina and zirconia crack growth simulations [16].

2.3.2. Algorithm. The configuration is considered unstable, and the associated flaw will grow while $K_{I}$ is higher than $K_{I 0}$.
TABle 3: Parameters for $\nu-K_{I}$ curves; $A$ and $m$ are extracted from [16].

\begin{tabular}{lcccc}
\hline & $A$ & $m$ & $K_{I C}(\mathrm{MPa} \sqrt{\mathrm{m}})$ & $K_{I 0}(\mathrm{MPa} \sqrt{\mathrm{m}})$ \\
\hline $\mathrm{Al}_{2} \mathrm{O}_{3}$ & $1.3 \times 10^{-23}$ & 40.0 & 4.2 & 2.1 \\
$\mathrm{ZrO}_{2}$ & $1.2 \times 10^{-18}$ & 20.0 & 5.2 & 2.7 \\
\hline
\end{tabular}

If $K_{I}$ is smaller than $K_{I 0}$, then tensile stress is too small to involve the flaw growth, so the configuration is considered stable. Thereafter, calculations were launched only for the unstable configurations $\mathrm{Ne}$; see Figure 7.

For each shock $N$ and every unstable configuration $\mathrm{Ne}$, the stress intensity factor is calculated, the crack velocity is deducted, and a new flaw size is determined. With this new flaw size, the stress intensity factor is recalculated and compared to $K_{I C}$. If $K_{I}$ is higher than $K_{I C}$, then the critical flaw size is reached, the cup is considered fractured, and the fractures counter $n F$ increases by 1 , Figure 8 . If $K_{I}$ is smaller 


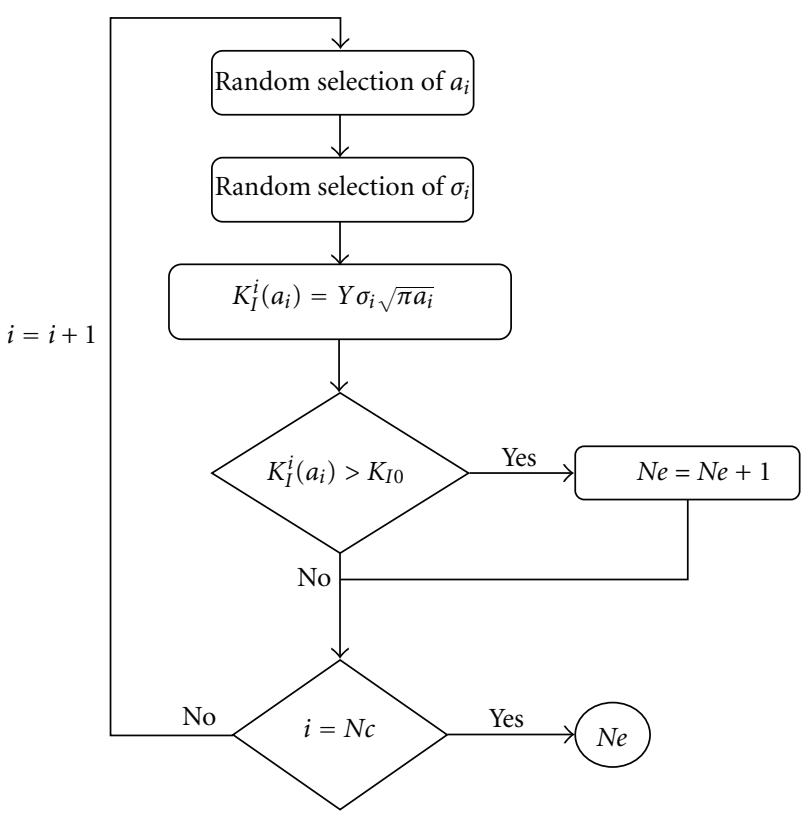

Figure 7: Algorithm for determining the number of unstable configurations.

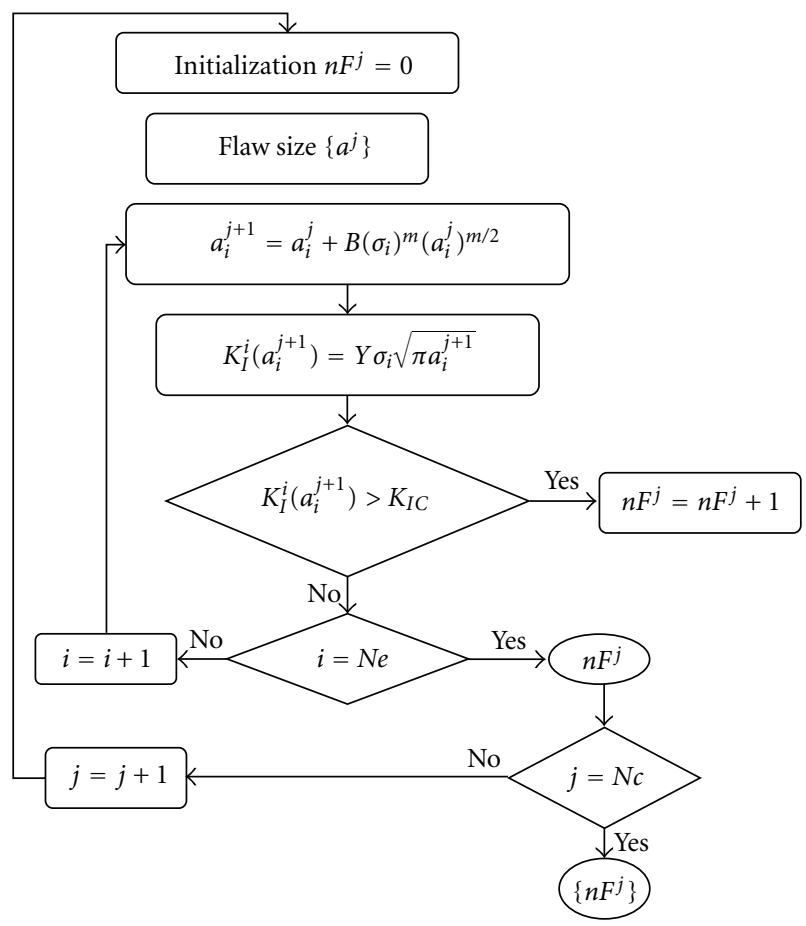

FIGURE 8: Algorithm for crack growth simulation.

than $K_{I C}$, then the configuration runs again. Therefore, the next configuration is considered. Finally, when all configurations are tested, the number of shocks increases, and the calculation begins again for all the unstable configurations.

Following this algorithm, Figure 8, iterations, up to $5 \cdot 10^{5}$, are numerous for reaching the final result. Thus a relation between a flaw size before and after the shock $j+1$ is established

$$
a_{j+1}=a_{j}+v_{j+1} \Delta t
$$

From (2) and (3),

$$
v_{j+1}=A Y^{m} \sigma^{m} \pi^{m / 2} a_{j}^{m / 2} .
$$

Hence,

$$
a_{j+1}=a_{j}+B \sigma^{m} a_{j}^{m / 2} ; \quad \text { where } B=A Y^{m} \pi^{m / 2} \Delta t .
$$

About the convergence problems, one paid attention that the number of shocks for cracking is a monotone function of $A$, $m$ and initial flaw size. Thus, the algorithm is useful, that is, the convergence is guaranteed, for estimating the prostheses lifetime [18].

2.3.3. Optimum of Configurations Number, Nc. Given that size and location of the flaws are randomly determined, test simulations were investigated in order to assess the optimal number of configurations $N c$ to use. Those simulations were performed for an assembly of head cup made from zirconia and inclined of $45^{\circ}$, with an applied force of $9 \mathrm{kN}$, a microseparation of $1.3 \mathrm{~mm}$, and a flaw initial average size of $40 \mu \mathrm{m}$. Hundreds of simulations were made for every number of configurations. The growth percentage, the standard deviation and the calculation time are shown in Figure 9 for $N c=10^{3}, 5 \times 10^{3}, 10^{4}, 5 \times 10^{4}, 10^{5}, 2 \times 10^{5}$, and $5 \times 10^{5}$.

The configurations number would be a compromise between the calculation time versus the growth percentage and the standard deviation. According to the results in Figure 9, one might suggest that considering $N c=10^{5}$ should be the best compromise in order to obtain a good repeatability of results with a moderate calculation time. Average calculation time for the $10^{5}$ configurations after shocking is $30 \mathrm{~s}$, which means $0.3 \mathrm{~ms}$ per configuration per shock. Since the average growth percentage is about $0.2 \%$, there will be 200 unstable configurations, which means a calculation time of $60 \mathrm{~ms}$ per shock. Thereby, the complete simulation of $10^{5}$ shocks might require a calculation time of one hour and 35 minutes if there is not preexisting cracks.

2.4. Probability of Failure. The previous algorithm, described in part 2, allows getting the $N_{c}$, number of tested configurations, and the $N_{F}$, number of failures. Thus $F$, the individual conditional probability, should be defined by

$$
F=\frac{N_{F}}{N_{c}}
$$

Moreover, thanks to probabilistic model developed by Todinov $[19,20]$, the probability evolution, $P$, might be calculated.

By making the hypothesis that there is no flaws coalescence and they evolve independently, the probability of failure, $P$, for an element under a constant loading $\sigma$ is

$$
P=1-\exp [-\lambda V F]
$$




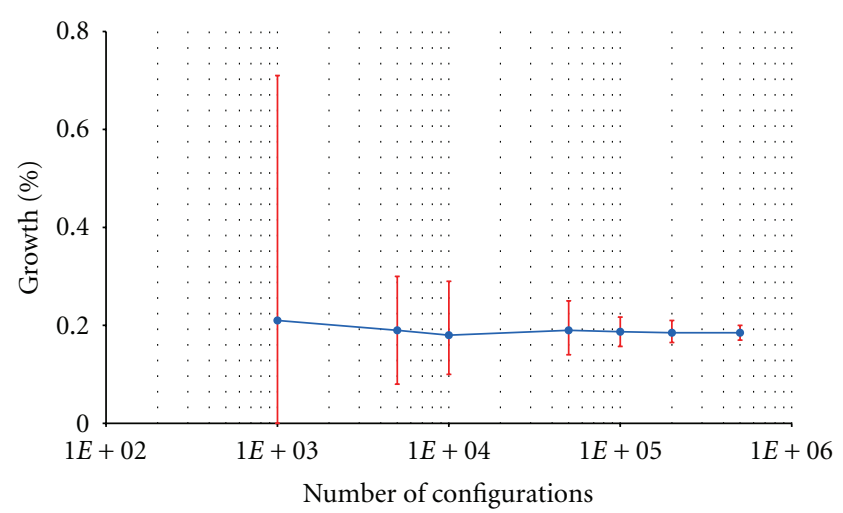

(a)

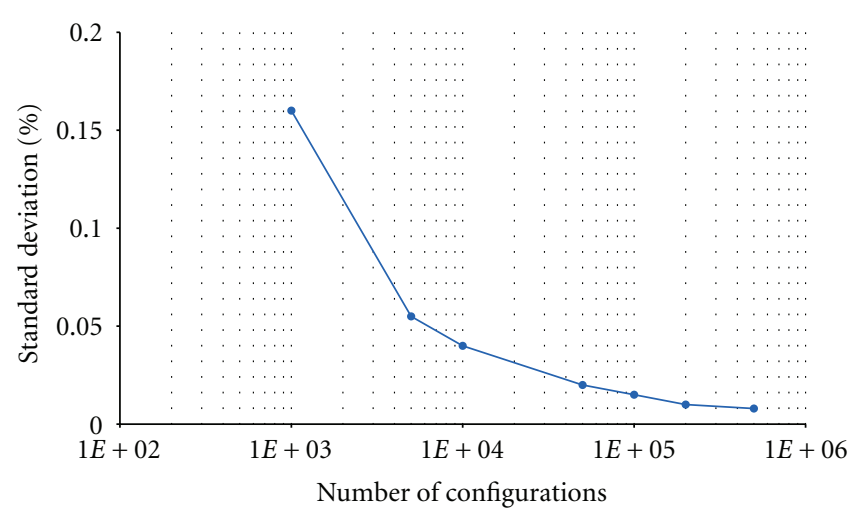

(b)

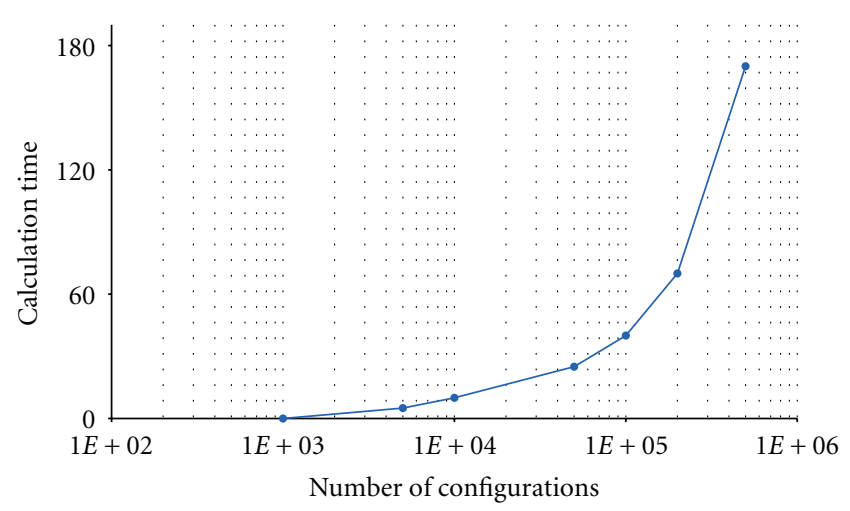

(c)

FIGURE 9: Determination of optimal number of configurations. (a) Average percentage of growth as function of the simulated number of configurations. Red dots represent minimum and maximum of percentage for every number of configurations. (b) Standard deviation of average percentage of growth. (c) Average calculation time, minutes, for detecting unstable flaws (according to the number of configurations).

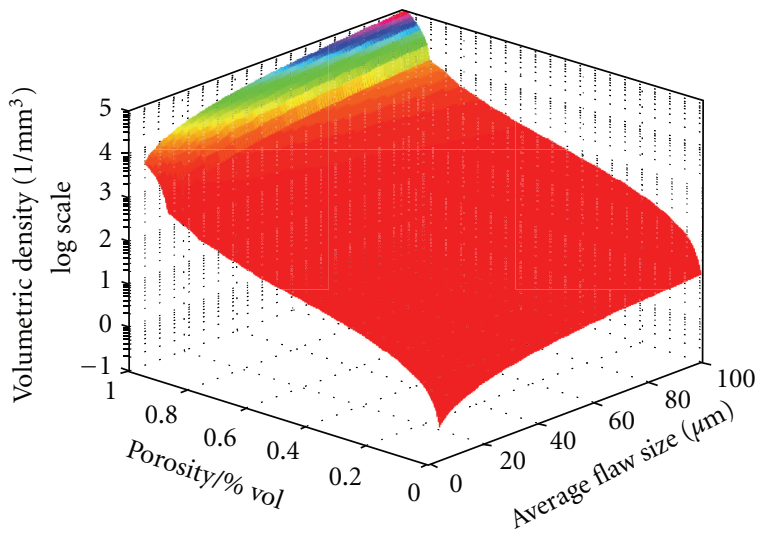

FIGURE 10: Determination of flaws density according to porosity and average flaw size.

where $\lambda$ is the density of flaws (the location of flaws is in accordance to a homogeneous Poisson distribution). $V$ is the volume, and $F$ is the individual conditional probability to involve a failure from a unique flaw [19]. This probability is conditional, because it represents the probability of failure initiated by flaws, with the hypothesis that this flaw is into the volume $V$. Flaws density $\lambda$ is calculated with the material porosity $p$, and the flaw average volume $V_{\alpha}$, both supposed spherical:

$$
\lambda=\frac{p}{(1-p) V_{\alpha}} .
$$

Assuming a porosity of the bioceramics from $0.01 \%$ to $1.00 \%$ and flaws average size between 1 and $100 \mu \mathrm{m}, \lambda$ is between 0.2 and $2.5 \times 10^{6}$; see Figure 10 .

\section{Results}

3.1. Stresses Distribution Using Finite Element Analysis (FEA): $A B A Q U S$. Various configurations will be considered in this part. One factor changes, and the others are constant: force, microseparation, angle, and materials. In this part, the flaws increasing will not be mentioned. One focuses the attention on the influence on the experimental parameters to better understand the influence of each one.

3.1.1. Force, Zirconia $28 \mathrm{~mm}$. In order to validate the crack growth model from experimental results, some modellings 

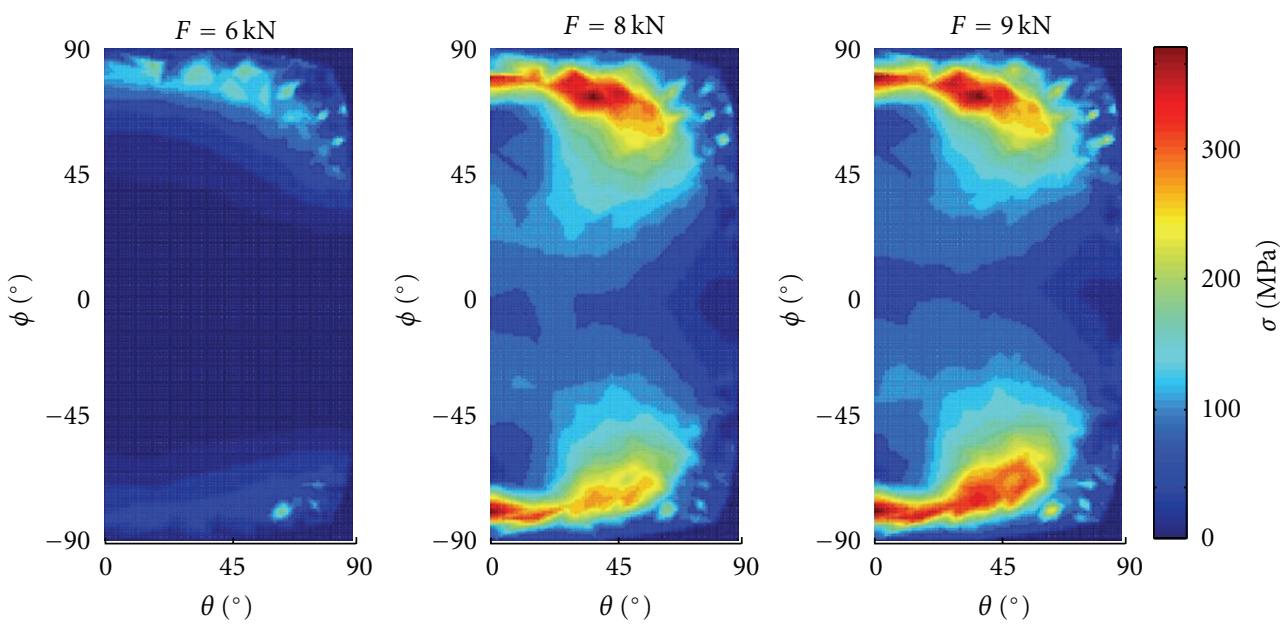

(a)

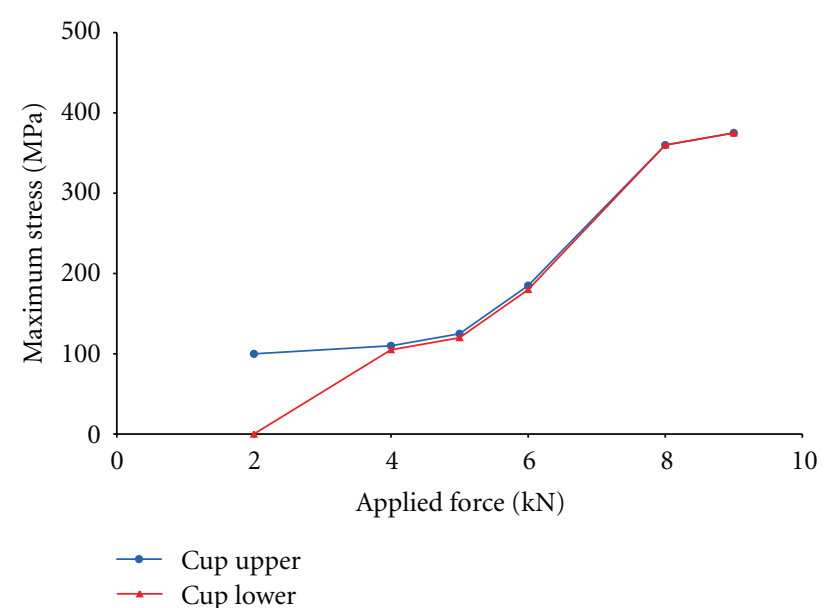

(b)

FIGURE 11: Influence of applied force on stresses on the cup, microseparation of $1.3 \mathrm{~mm}$, and angle of $45^{\circ}$. (a) Location of tensile stresses on the cup under a force of 6,8 , and $9 \mathrm{kN}$. (b) Maximum stresses as function of the applied force.

were investigated for a cup tilted at $45^{\circ}$, with former microseparation from 0.0 to $1.3 \mathrm{~mm}$ and a force between 2 and $9 \mathrm{kN}$. First, a contact between the head and the upper rim of the cup takes place. Then, the head impacts the upper rim of the cup, rebounds, and impacts the lower rim at the end of simulation, and the duration of this movement is $11 \mathrm{~ms}$.

On the cup, the maximum stresses were always located near the rim; see Figure 11(a). The applied force did not change the stresses location but only its magnitudes. Moreover, for $2 \mathrm{kN}$, stresses are located on the upper rim of the cup. In fact, the shock is not strong enough to involve the head rebound and impact the lower rim.

For higher forces, stresses are also observed on the lower rim of the cup. However, stresses on the upper rim are slightly greater than those on the lower rim; see Figure 11(b).

This phenomenon, probably related to rebounds at the lower and the upper rims, is likely to appear in the experimental tests, since two wear stripes were located on the head. These results corroborate exactly some explants studies
$[5,21,22]$ after each impact the stresses are not constant, thus the maximum stresses are time dependent.

3.1.2. Microseparation, Zirconia $28 \mathrm{~mm}$. The influence of the microseparation was investigated with a cup position of $45^{\circ}$ and a force of $9 \mathrm{kN}$. Three vertical displacements were $0,0.5,0.75,1.0,1.25$, and $1.5 \mathrm{~mm}$, which correspond respectively to these microseparations: $0,0.7,1.0,1.3,1.6$, and $1.9 \mathrm{~mm}$. As mentioned above, stresses are located on the upper rim and the lower rim of the cup, Figure 12. The lower microseparation multiplied the stress by a factor of 100 on the cup's surface, compared with the case without microseparation.

Tensile stress of $400 \mathrm{MPa}$ in Figure 12 was obtained after first impact. Stresses are shown for the upper and lower rim of the cup. The femoral head impacts the upper rim of the cup and then the lower one and so on until the end in $t=11 \mathrm{~ms}$. This phenomenon has not been proved in vivo, but it might exist when testing bearing surfaces in 

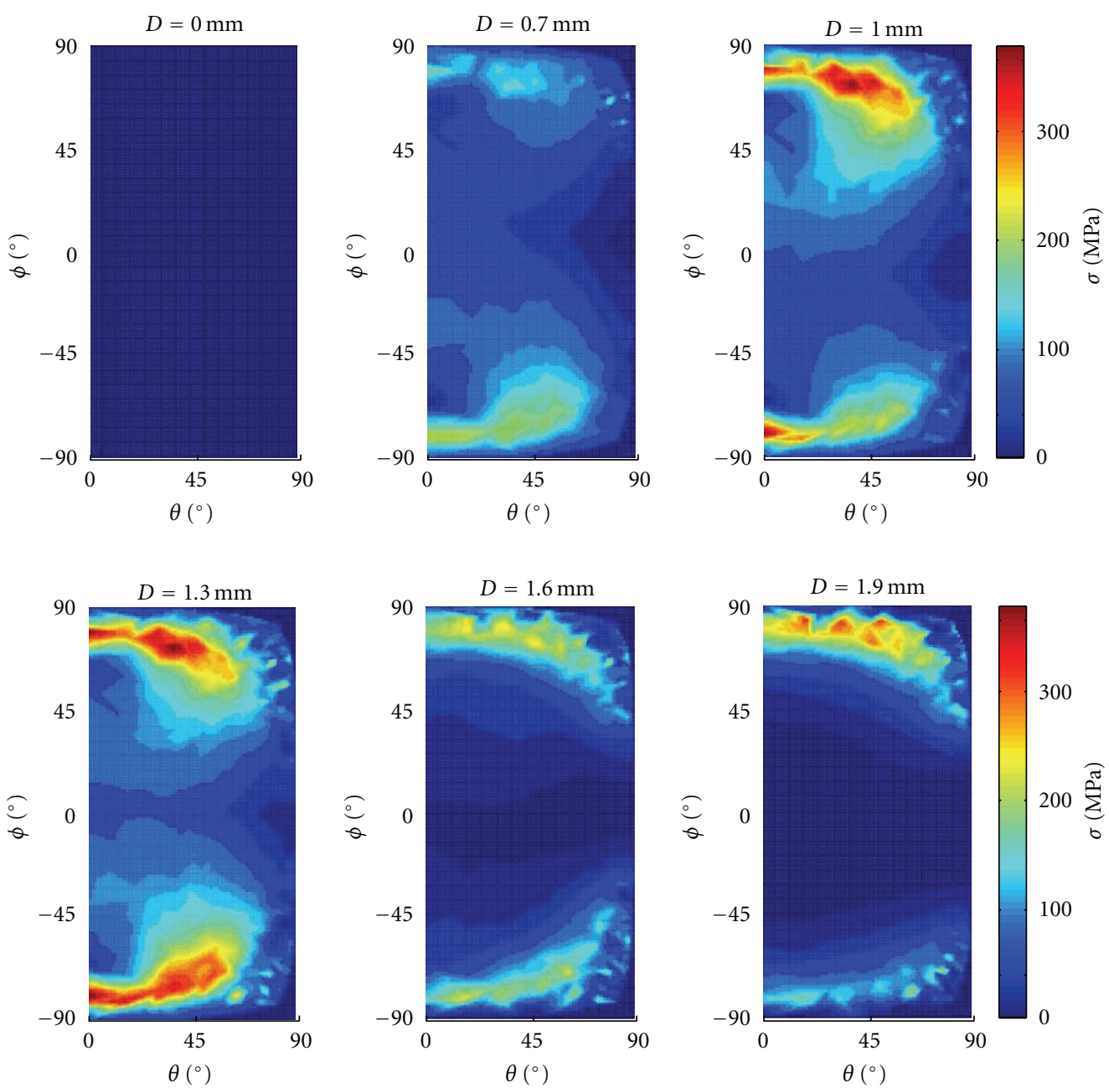

FIGURE 12: Influence of microseparation on the surface stresses of the cup; tensile stresses on the cup for 0, 0.7, 1.0, 1.3, 1.6, and 1.9 mm.

shock device since two wear stripes are observed on the head (upper and lower). Maximum stresses are located near the upper rim on the cup. The worst case leading to biggest stresses is a microseparation between 1.0 and $1.5 \mathrm{~mm}$. This threshold of microseparation for maximum stress is valid for bearing surfaces of diameter $28 \mathrm{~mm}$. For femoral heads with a different geometry, the value of microseparation leading the maximum stresses could vary. Moreover, in the finite element modelling, the cup is constrained in all degrees of freedom, while in the shock device, the cup has one degree of freedom in the axis perpendicular to the applied force. Some investigations are in progress in order to determine the elastic response of the cup in the shock device. Thus, an elastic and damping coefficients could be input to the finite element model, modifying the boundary conditions and leading to different values of stresses on the cup.

3.1.3. Inclination, Zirconia $28 \mathrm{~mm}$. The influence of the cup angle, the inclination, was studied for $30^{\circ}, 45^{\circ}$, and $60^{\circ}$; see Figure 13(a). For each angle, the load was of $9 \mathrm{kN}$. The modelling was investigated for several microseparation values: $0,0.7,1.0,1.3$, and $1.6 \mathrm{~mm}$. The location of the maximum stress, on the cup surface, does not depend on the inclination of the cup; however, the maximum value does; see Figure 13(b).

3.1.4. Material, Zirconia $28 \mathrm{~mm}$ and Alumina $28 \mathrm{~mm}$. An alumina-alumina prosthesis of $28 \mathrm{~mm}$ was considered, mounted at $45^{\circ}$, with a force of $9 \mathrm{kN}$. Stresses on the cup were $30 \%$ higher than stresses on the zirconia one. Results are shown on Figure 14.

3.2. Algorithm of Crack Growth Using Matlab. In this part, the Todinov's approach is investigated for predicting the crack growth according to a flaws distribution. Positions of the flaws are shown in Figure 15. Both kinds of coordinates are considered: spherical coordinates (phi-theta), Figure 15(a), and Cartesian coordinates $(x-y)$, Figure 15(b). In Figure 15(a), the flaws are represented. The dots are related to zone and the depth of flaws. For better understanding and clarity, only a part of flaw is represented on this graph. Figure 15(b) highlights the lowest and the highest sizes of flaws. The flaws are represented thanks to the same color scale than the one used for Figure 15(a). The fracture 

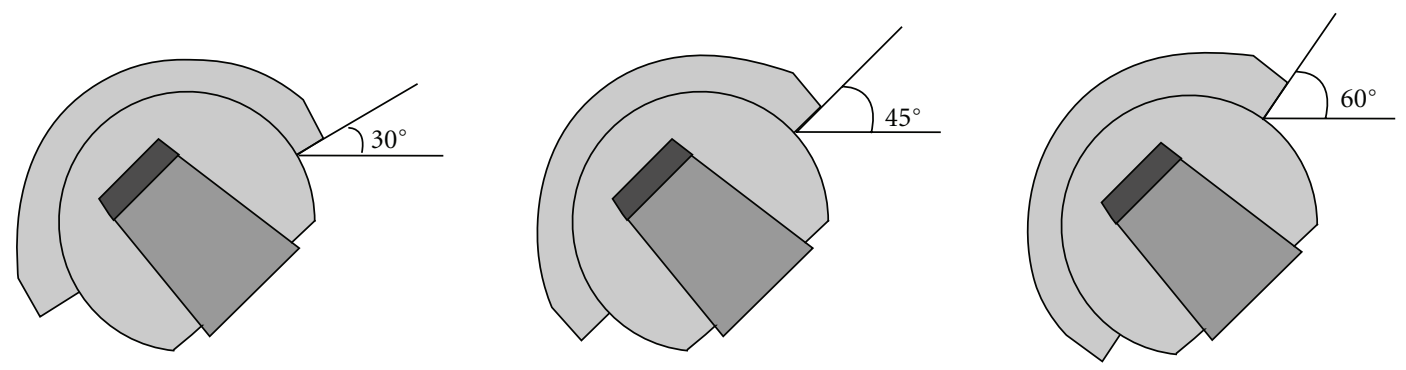

(a)
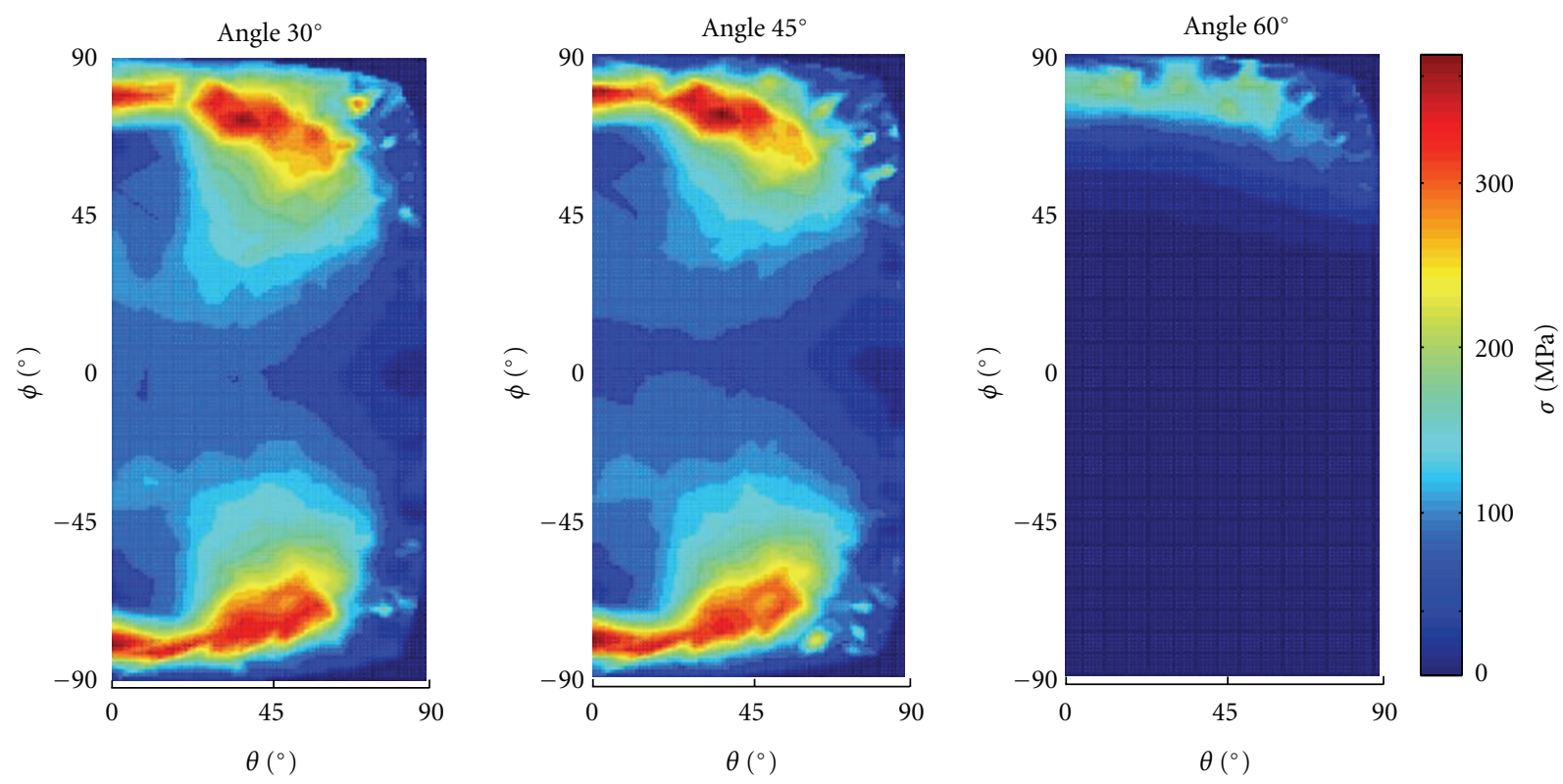

(b)

FIGURE 13: Influence of inclination on the surface stresses of the cup. (a) Tested inclinations. (b) Stresses on the surface of the cup for each inclination and a microseparation of $1.3 \mathrm{~mm}$.
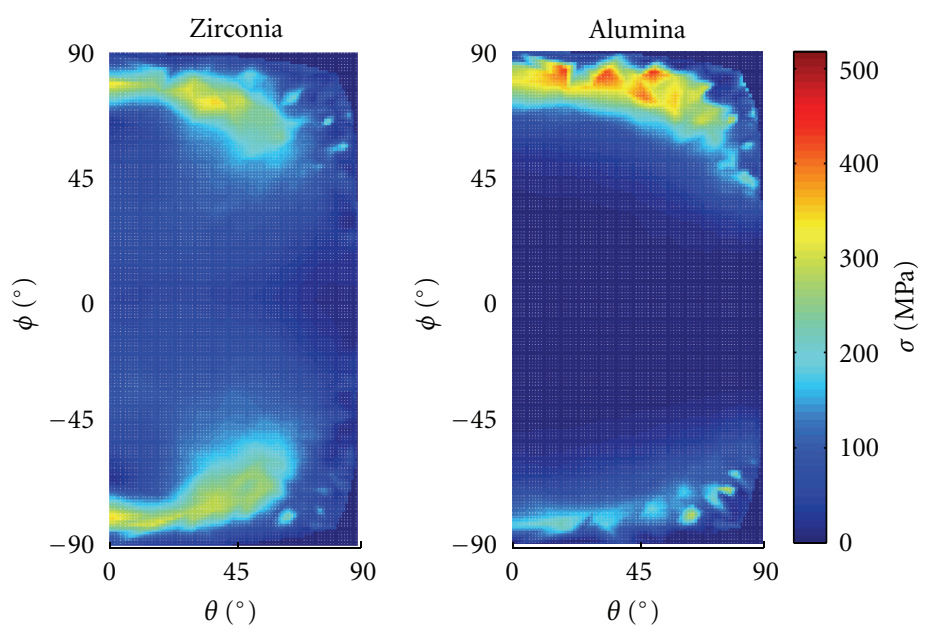

FIGURE 14: Influence of material on the surface stresses on the cup, with a load of $9 \mathrm{kN}$, inclination of $45^{\circ}$, and microseparation of $1.3 \mathrm{~mm}$. 


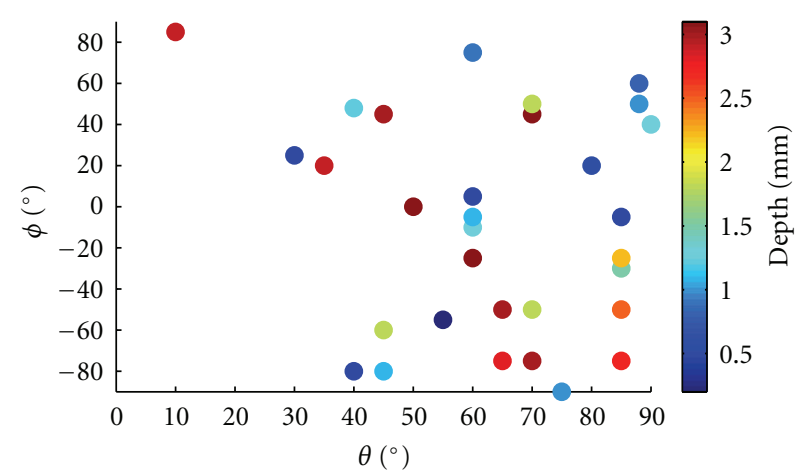

(a)

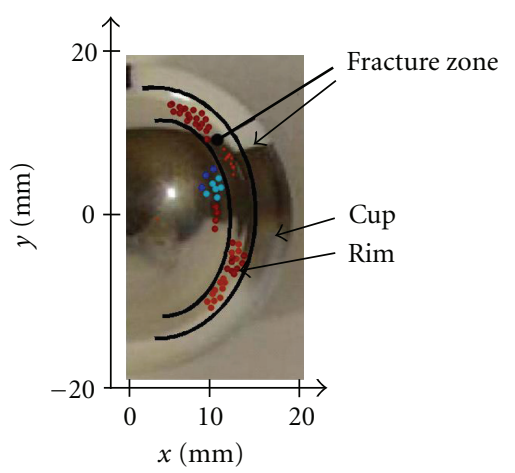

(b)

FigURe 15: Location of simulated flaws, cup inclined at $45^{\circ}$, load of $9 \mathrm{kN}$ and microseparation of $1.3 \mathrm{~mm}$. (a) Location of critical flaws for a flaw size between 19 and $35 \mu \mathrm{m}$; colored points are related to the zone of defects, nonexhaustive graph. (b) Crack surfaces observed experimentally on an alumina cup and location of simulated flaws, only lowest and highest sizes of flaws are represented.
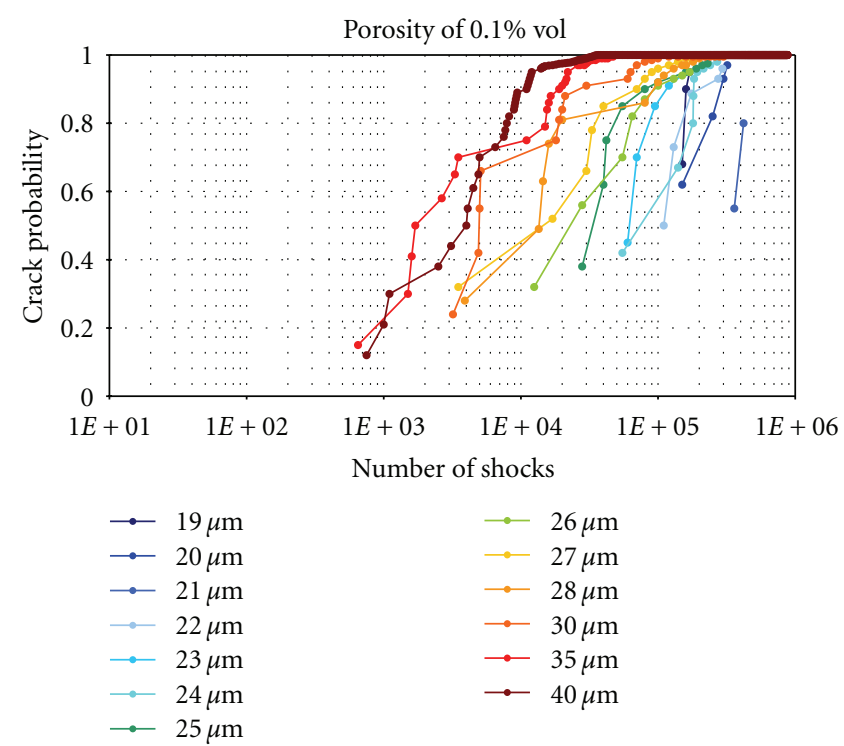

IGURE 16: Evolution of crack probabilities versus the number of shocks, according to flaw size (from 19 to $40 \mu \mathrm{m}$ ) and porosity, (a) $0.1 \%$ vol and (b) $0.7 \%$ vol; all following parameters are constant, inclination angle of $45^{\circ}$, load of $9 \mathrm{kN}$ and microseparation of $1.3 \mathrm{~mm}$.

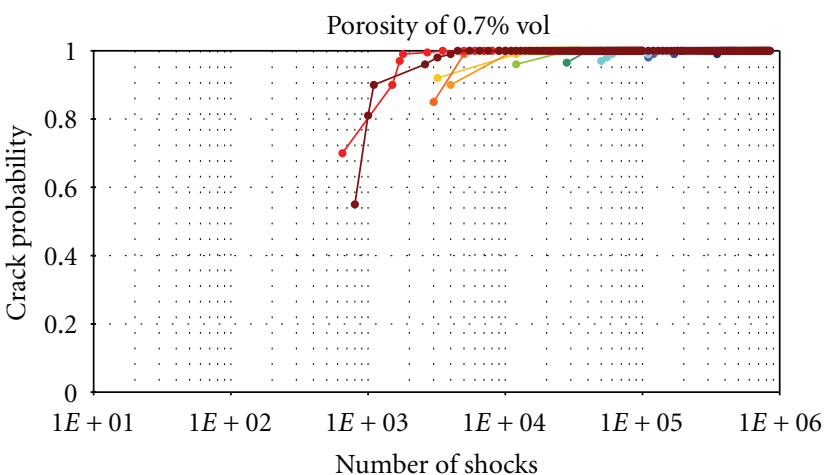

$\longrightarrow 19 \mu \mathrm{m}$
$\because 20 \mu \mathrm{m}$
$\rightarrow 21 \mu \mathrm{m}$
$\rightarrow 22 \mu \mathrm{m}$
$\rightarrow 23 \mu \mathrm{m}$
$\rightarrow 24 \mu \mathrm{m}$
$\rightarrow 25 \mu \mathrm{m}$

$\rightarrow 26 \mu \mathrm{m}$

$\because 27 \mu \mathrm{m}$

$\rightarrow 28 \mu \mathrm{m}$

$\longrightarrow 30 \mu \mathrm{m}$

$\rightarrow 35 \mu \mathrm{m}$

$\rightarrow \quad 40 \mu \mathrm{m}$

(b) zone is highlighted, and it is located at the boundary between dark and light areas.

There was no critical flaw deeper than $3 \mathrm{~mm}$. Moreover, these critical flaws seemed to be distributed on almost all the surface of the cup, Figure 15(a), on the theta-phi coordinates. When the coordinates are Cartesian, Figure 15(b), deepest flaws and the ones at the surface are located at the rim of the cup. The fracture zone is in the area of deepest flaws.

This approach is macroscopic. Any investigation was carried out at the microscale, and this means that taking into account the grain structure is not considered in this study. However, the deepest flaws are related to the fracture zone. From the point of view of manufacturing, if defects are in the bulk alumina and if they are higher than $10 \mu \mathrm{m}$, the failure of the cup is promoted. Figure 15(b) highlights the fracture on a tested cup is in the same zone than the ones showed from the modelling [23].

\subsubsection{Probability of Failure}

Influence of Porosity on Failure Probability. As mentioned before, material flaws density directly depends on the material porosity (9). Calculations were made with several porosities, ranging from $0.1 \%$ to $1.0 \%$ vol. Figure 16 highlights the results of $0.1 \%$ and $0.7 \%$ vol of porosity. At the lowest porosity, the number of shocks increases in order to obtain the same crack probability. For a porosity higher than $0.7 \%$, the less critical flaw leads to a failure probability higher than 0.9 . 


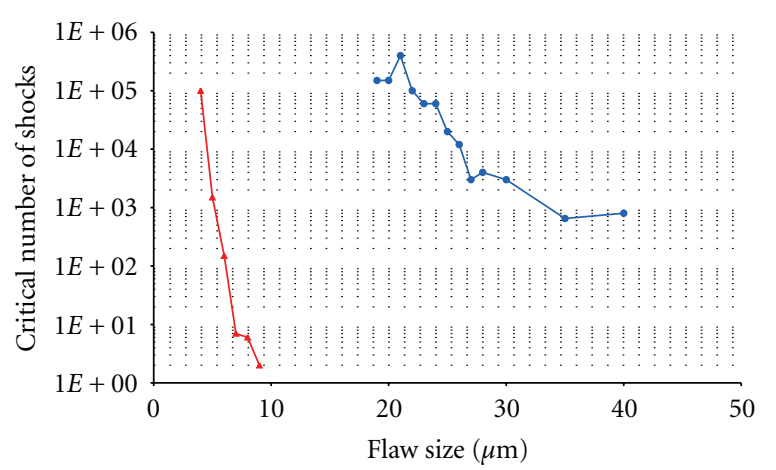

$\rightarrow$ Alumina

$\rightarrow$ Zirconia

FIGURE 17: Influence of material on critical number of shocks.

Influence of Material on Failure Probability. The modelling parameters are as follows: zirconia-zirconia and aluminaalumina, head diameter of $28 \mathrm{~mm}$, inclination of $45^{\circ}$, force of $9 \mathrm{kN}$ and microseparation of $1.3 \mathrm{~mm}$. The minimum flaws sizes likely to growth in alumina are smaller than those for zirconia: $4 \mu \mathrm{m}$ and $19 \mu \mathrm{m}$, respectively, Figure 17 .

3.3. Comparison of Maximum Number of Shocks. The main aim of this work is to present if zirconia or alumina materials involve the highest shock number according to the flaw size. If the shocks number is weak and the flaw size is lower than $10 \mu \mathrm{m}$, one might suggest that flaws, providing from the sintering process, could involve the structure failure under shocks.

Finally, four modellings were investigated: head diameters of $28 \mathrm{~mm}$ and $32 \mathrm{~mm}$ for alumina and zirconia. The inclination was constant and equal to $45^{\circ}$, the load was of $9 \mathrm{kN}$, and the microseparation was of $1.3 \mathrm{~mm}$. Alumina $32 \mathrm{~mm}$ with a thick cup appears to be more resistant to shocks than alumina diameter $28 \mathrm{~mm}$; see Figure 18(a). However, the zirconia diameter does not exhibit a significant influence, Figure 18(b). The critical flaw sizes of zirconia are three times higher than the ones of alumina.

\section{Discussion}

4.1. Finite Element Analysis. The finite element analysis allowed highlighting the significant parameters for the crack growth modelling (stresses) and establishing the mechanical behaviour description. Concerning the values of stresses, it is worth noting that the head is subjected to compressive stresses, whereas the cup is mainly subjected to tensile stresses more harmful. In addition, a weak microseparation has a huge influence on location of stresses. Thus, microseparation produced a stresses concentration at the rim of cup, experimental tests exhibit, too, a fracture at the rim of the cup. Rebounds and conflicts between head and cup, when the hydraulic jack go down involved two wear zones, at the upper and the lower part of the cup, which matched with the two wear stripes during the experimental tests.
Moreover, the stress maximum only depended on the head velocity before impacting the cup. In fact, this maximum is also influenced by the mechanical behaviour of the assembly.

Three inclinations were then tested: $30^{\circ}, 45^{\circ}$, and $60^{\circ}$. When the cup is mounted at $60^{\circ}$ the smaller maximum of stress is obtained regardless of the microseparation.

This simulation also highlighted the differences between the two types of tested bioceramics, zirconia and alumina. Alumina is submitted to higher compressive stresses than zirconia, since its Young's modulus is two times higher. Finally, the worst case would be described in the following conditions: load of $9 \mathrm{kN}$; microseparation of $1.3 \mathrm{~mm}$, inclination of $30^{\circ}$ and alumina material. The inclination depends on the anatomical factors. The usual surgical inclination is within the range from $35^{\circ}$ to $60^{\circ}$ [24]. From Brodner et al. [25], the hip rotation is not limited by the inclination. The inclination affects the stresses distribution on the cup. From the presented results, we should recommend that the inclination should be higher than $45^{\circ}$. However, we did not investigate all mobility angles, anteversion, varus and valgus prosthesis orientation, and so on.

4.2. Crack Growth Modelling. Nevertheless, severe modelling hypotheses were considered, and these results (in terms of lifetime and location of critical flaws) are in good agreement with the experimental tests; see Figure 15. The algorithm of crack growth, based on Todinov's equations, was used to estimate the probability of failure which depended on the stresses on the material and the rate growth of the flaws. The iterative nonlinear equation (6) used to evaluate the evolution of a flaw size was tested with several growth laws and its deterministic behaviour was satisfied. Thus, this deterministic equation was inserted in the algorithm for estimating ceramic elements lifetime.

The validation of results was made by comparing theoretical and experimental lifetime for zirconia-zirconia contact. The order of magnitude, that is, the lifetime, was similar regardless of the fact that crack growth laws were taken from literature [15] and did not exactly correspond to tested biomaterials. Additionally, the theoretical location of critical flaws likely to induce a crack was in agreement with the optical observations; see Figure 15; flaws were located on the wear stripes on the femoral head surface. This comparison with experimental results got a clue for validating the model. A model combining FEA and postprocessing was also implemented for crack growth simulation.

4.3. Most Significant Parameters. The studied parameters were: material, head diameter (consequently cup diameter), cup geometry applied force, inclination and microseparation. Excluding the applied force which has an obvious influence on the lifetime of the prosthetic elements, microseparation and probably inclination of the cup seem to be both significant parameters.

The inclination has an influence on the probability of failure. From previous investigations [18], one might suggest that the inclination of $60^{\circ}$ involved the lowest failure probability, whereas when inclined at $30^{\circ}$, stresses are too 


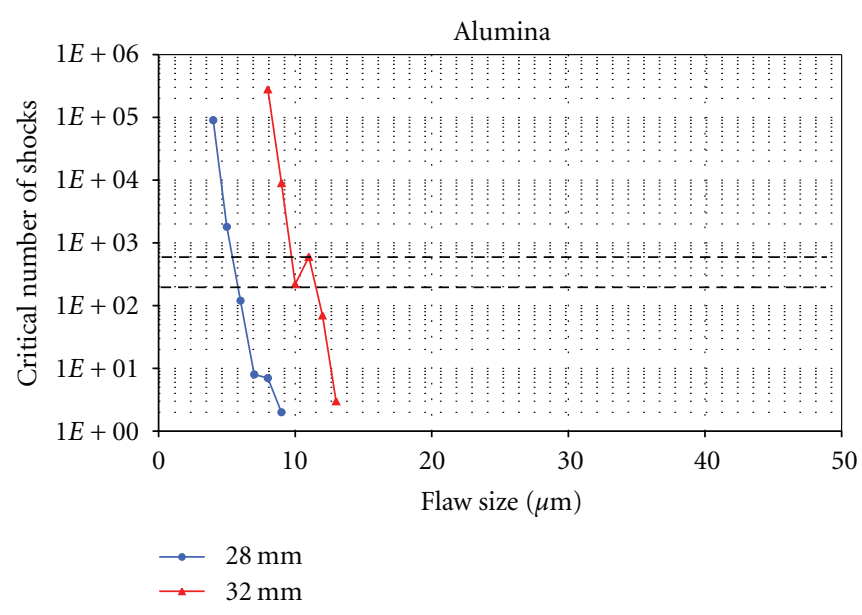

(a)

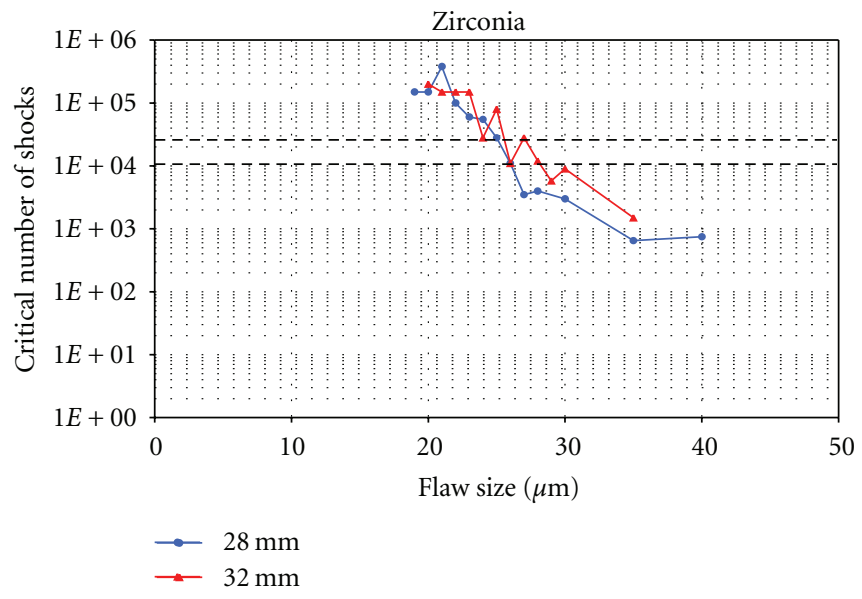

(b)

FIGURE 18: Influence of geometry on critical number of shocks. Critical number of shocks as function of flaw size for (a) alumina and (b) zirconia. Dotted lines correspond to the interval of lifetime found experimentally.

much higher. Nonetheless, a very vertical inclination might increase the risk of impingement, which consists of intermittent contacts between the cone and the rim of the cup. This phenomenon has been reported to produce several in vivo fractures of ceramic cups [26]. One might expect that the implants positioning is a key factor for improving the implants lifetime. The positioning includes the inclination, as described in this work, but it involves the global positioning of the femoral stem, that is, the location of the cup in the acetabulum, the height of head on the femoral neck, the sizing of the assembly of head and cup, and so forth. All these factors should be relevant and they are not investigated during this work. It should be relevant for treating this problem about ceramic materials as artificial hip joint. This problem is related to the kind of head and cup assembly. Indeed, a smooth (polymer as UHMWPE)-hard (metal or ceramic) assembly involves no significant mismatches if the centres of the spheres are not coinciding. On the contrary, a hard-hard assembly involves severe degradations if mismatching. We got a clue to show that the shocks, due gait cycle with microseparation, influence hugely the lifetime of ceramic cup. These mismatchings should decrease the lifetime duration. Moreover, the clearance, the deviation of head and cup radii, plays a significant role [27]. This radius difference is about few hundred micrometers. One might suggest for optimizing the clearance in order to improve the CoC assembly lifetime.

In the model, after the impact head cup, only the compressive stresses on the head were taken into account. Nevertheless, there could be important tensile stresses on the femoral head created by the taper fit. Further investigations should be made in order to confirm if these tensile stresses could lead to fracture on the femoral head as observed in vivo.

4.4. Limitations of the Investigating Modelling. The elastic recovery of the actuator of the cup was not taken into account. Additional investigations will be in progress for taking into account the mechanical impedance of the device. Concerning the FEA, the contact head cup was supposed frictionless, whereas during the tests, a wear stripe due to sliding movement was observed. The materials were assumed perfectly elastic, but at microscale, some plastic deformations could occur. A limited number of elements were chosen to have reliable results, only for the more solicited zones. Thus, it would be interesting to refine the mesh in the volume, with the aim of confirming that stresses are mostly located on the surface. Nevertheless, refining the mesh would increase the calculation time. In this study, the purpose was to obtain reliable results even by meshing roughly, since $2 \mathrm{D}$ results were interpolated with a refined mesh which multiplied the elements. Crack growth laws, crack rate as function of the stress intensity factor, were taken from literature. These values should be determined for the materials tested in the present study, but it would need a lot of time. Therefore, the crack growth law was developed only for a flaw supposed spherical. In addition, theoretical estimations of lifetime are in agreement with the experimental results for zirconia and alumina, which suggests that the crack growth curves used are not too different to the actual case.

\section{Conclusions}

The modelling confirmed the hypotheses concerning the assembly head cup. It has been demonstrated that the minor microseparation involves a huge influence. Moreover, the cup is subjected to tensile stresses, whereas the head is subjected to compressive stresses. The modelling also confirmed the location of high stressed zones at the rim of the cup, corresponding to location of wear stripes on the heads from the experimental tests. Crack growth algorithm is based on the stresses calculated by finite elements analysis. Despite the simplifying hypotheses and the crack growth curves taken from literature, results are on agreement with the experimental observations. In fact, all the simulated flaws likely to induce rupture are located on the cup surface 
corresponding to wear stripes on the head. Furthermore, the equation to calculate probabilities of failure takes into account the porosity. This model combining FEA with crack growth modellings confirmed the hypotheses made during experimental tests. In addition, this model served to theoretically testing parameters not studied experimentally. Thus, the inclination of the cup seems to play a significant role in the hip prostheses degradation. It has also been shown that microseparation produces wear stripes and flaws on the cup surface which might lead to the fracture. Given that wear stripes appear early on the head during in vitro tests, more attention must be paid to this phenomenon even if it appears occasionally in vivo. Crack growth modelling revealed other significant parameters in cup lifetime like inclination of the cup and porosity of the bulk material. Thus, for an alumina cup with a porosity higher than $0.7 \%$, the less critical flaw leads to a failure probability higher than 0.9 . In fact, for porosity $0.8 \%$, these flaw sizes lead in densities higher than those for zirconia, thus the minor critical flaw in alumina will lead probabilities of failure near to unity. Consequently, estimating lifetime by means of critical number of shocks is also valid for alumina.

An interesting development concerning FEA could be refining the cup mesh in $3 \mathrm{D}$. One should pay attention to calculating more accurate stresses and verifying that they are mainly located on the surface rather than the bulk cup. A submodel could be made with only the rim of the cup, since the bottom does not take part in the global kinetics of the head-cup assembly. Given that at the microscale some plastic deformation could occur in the cup, plastic properties should be set to alumina and zirconia. A multiscale approach should be developed for understanding the crack initiation and evolution from the microscopic, which is grain scale to macroscopic scale. Concerning the crack growth algorithm, the three-dimensional flaws should be investigated instead of only those on the surface and with a nonspherical shape but ellipsoidal. Thus, it would be necessary to give a specific orientation to each flaw. This study could be the base for developing new tests as closer as possible to in vivo degradations. Nevertheless, it seems absolutely necessary to continue the shock tests, since the principal cause of cup failure is the fracture instead of an excessive wear. Thus, if ceramics are shocks resistant they could be used without risk of fracture with a superior in vivo lifetime. Additional investigations are in progress. Thus, this original study opens the way for further research.

\section{Financial Relations}

The authors do not have a direct financial relation with the commercial identity mentioned in this paper that might lead to a conflict of interests for any of the authors.

\section{Conflict of Interests}

The authors declare that there is no conflict of interests.

\section{Acknowledgments}

The authors are grateful to: (i) ANR (Agence Nationale de la Recherche) for granting the project "Opt-Hip"; (ii) Region
Rhône-Alpes provided funding for a Ph.D. grant about this work; and (iii) Nicolas Curt for his technical contribution about the shocks device. Their institution is responsible about the licences. Due to ethics rules, They had to notice the licence when they investigated works with specific software.

\section{References}

[1] P. Boutin, "Arthroplastie totale de hanche par prothèse en alumine frittée," Revue de Chirurgie Orthopédique et Réparatrice de l'Appareil Moteur, vol. 58, no. 3, pp. 229-246, 1972.

[2] P. Boutin and D. Blanquaert, "Le frottement aluminealumine en chirurgie de la hanche. 1205 arthroplasties totales: Avril 1970-Juin 1980," Revue de Chirurgie Orthopédique et Réparatrice de l'Appareil Moteur, vol. 67, pp. 279-287, 1970.

[3] P. Boutin, P. Christel, J. M. Dorlot et al., "The use of dense alumina-alumina ceramic combination in total hip replacement," Journal of Biomedical Materials Research, vol. 22, no. 12, pp. 1203-1232, 1988.

[4] P. Bizot, R. Nizard, and L. Sedel, "Le couple alumine-alumine dans les prothèses totales de hanche. de la théorie a la pratique," Online edition, 2010, http://www.maitrise-orthop.com/ viewPage. do? $\mathrm{id}=619$.

[5] E. A. Magnissalis, T. A. Xenakis, and C. Zacharis, "Wear of retrieved ceramic THA components-four matched pairs retrieved after 5-13 years in service," Journal of Biomedical Materials Research, vol. 58, no. 5, pp. 593-598, 2001.

[6] J. Nevelos, E. Ingham, C. Doyle et al., "Microseparation of the centers of alumina-alumina artificial hip joints during simulator testing produces clinically relevant wear rates and patterns," Journal of Arthroplasty, vol. 15, no. 6, pp. 793-795, 2000.

[7] T. Shishido, K. Yamamoto, S. Tanaka, T. Masaoka, I. C. Clarke, and P. Williams, "A study of a retrieved implant of ceramicon-ceramic total hip arthroplasty," Journal of Arthroplasty, vol. 21, no. 2, pp. 294-298, 2006.

[8] T. Yamamoto, S. Masanobu, U. Masaru, H. Takehito, T. Yusuke, and Y. Kazuo, "Wear analysis of retrieved ceramic-onceramic articulations in total hip arthroplasty: femoral head makes contact with the rim of the socket outside of the bearing surface," Journal of Biomedical Materials Research B, vol. 73, no. 2, pp. 301-307, 2005.

[9] A. V. Lombardi, T. H. Mallory, D. A. Dennis, R. D. Komistek, R. A. Fada, and E. J. Northcut, "An in vivo determination of total hip arthroplasty pistoning during activity," Journal of Arthroplasty, vol. 15, no. 6, pp. 702-709, 2000.

[10] Tzanck-Ortho, 2007, http://patient.tzanck-ortho.fr/page5/ page24/page24.html.

[11] J. P. Paul, "Comparison of EMG signals from leg muscles with the corresponding force actions calculated from walk path measurements," Human Locomotor Engineering, vol. 48, pp. 626, 1971.

[12] J. P. Paul and D. A. McGrouther, "Forces transmitted at the hip and knee joint of normal and disabled persons during a range of activities," Acta Orthopaedica Belgica, vol. 41, no. 1, pp. 78$88,1975$.

[13] T. P. Andriacchi and D. E. Hurwitz, "Gait biomechanics and the evolution of total joint replacement," Gait and Posture, vol. 5, no. 3, pp. 256-264, 1997.

[14] J. Hausselle, M. Dursapt, J. Stolarz, and B. Forest, "Shock induced damages on hip prostheses," in Proceedings of the 20th European Conference on Biomaterials, 2006.

[15] J. Chevalier, C. Olagnon, G. Fantozzi, and B. Cales, "Subcritical crack growth and thresholds in a 3Y-TAP ceramic under 
static and cyclic loading conditions," Ceramics International, vol. 23, no. 3, pp. 263-266, 1997.

[16] J. Chevalier, C. Olagnon, and G. Fantozzi, "Crack propagation and fatigue in zirconia-based composites," Composites A, vol. 30, no. 4, pp. 525-530, 1999.

[17] A. H. De Aza, J. Chevalier, G. Fantozzi, M. Schehl, and R. Torrecillas, "Crack growth resistance of alumina, zirconia and zirconia toughened alumina ceramics for joint prostheses," Biomaterials, vol. 23, no. 3, pp. 937-945, 2002.

[18] J. Hausselle, Etude de la dégradation par chocs de têtes et cupules de prothèses de hanche en biocéramique, Ph.D. thesis, SGM, 2007, http://tel.archives-ouvertes.fr/docs/00/48/94/72/PDF/JHausselle-071213.pdf.

[19] "La théorie du chaos," Ed Flammarion, Manchecourt, 1987.

[20] M.T. Todinov, "Probability of fracture initiated by defects," Materials Science and Engineering A, vol. 27, no. 1-2, pp. 3947, 2000.

[21] M.T. Todinov, "Equations and a fast algorithm for determining the probability of failure initiated by flaws," International Journal of Solids and Structures, vol. 43, no. 17, pp. 5182-5195, 2006.

[22] W. L. Walter, G. M. Insley, W. K. Walter, and M. A. Tuke, "Edge loading in third generation alumina ceramic-on-ceramic bearings: stripe wear," Journal of Arthroplasty, vol. 19, no. 4, pp. 402-413, 2004.

[23] M. Manaka, I. C. Clarke, K. Yamamoto, T. Shishido, A. Gustafson, and A. Imakiire, "Stripe wear rates in alumina THR - comparison of microseparation simulator study with retrieved implants," Journal of Biomedical Materials Research B, vol. 69, no. 2, pp. 149-157, 2004.

[24] J. Hausselle, S. Drapier, J. Geringer, M. Dursapt, J. Stolarz, and B. Forest, "Flaws growth modelling in zirconia acetabular cups of hip prostheses under microseparation," Mecanique et Industries, vol. 9, no. 2, pp. 153-158, 2008.

[25] W. Brodner, A. Grübl, R. Jankovsky, V. Meisinger, S. Lehr, and F. Gottsauner-Wolf, "Cup inclination and serum concentration of cobalt and chromium after metal-on-metal total hip arthroplasty," Journal of Arthroplasty, vol. 19, no. 8, pp. 66-70, 2004.

[26] F. J. Kummer, S. Shah, S. Iyer, and P. E. DiCesare, "The effect of acetabular cup orientations on limiting hip rotation," Journal of Arthroplasty, vol. 14, no. 4, pp. 509-513, 1999.

[27] M. J. H. McCarthy and M. Halawa, "Lining up the liner. 2 case reports of early ceramic liner fragmentation," Journal of Arthroplasty, vol. 22, no. 8, pp. 1217-1222, 2007. 

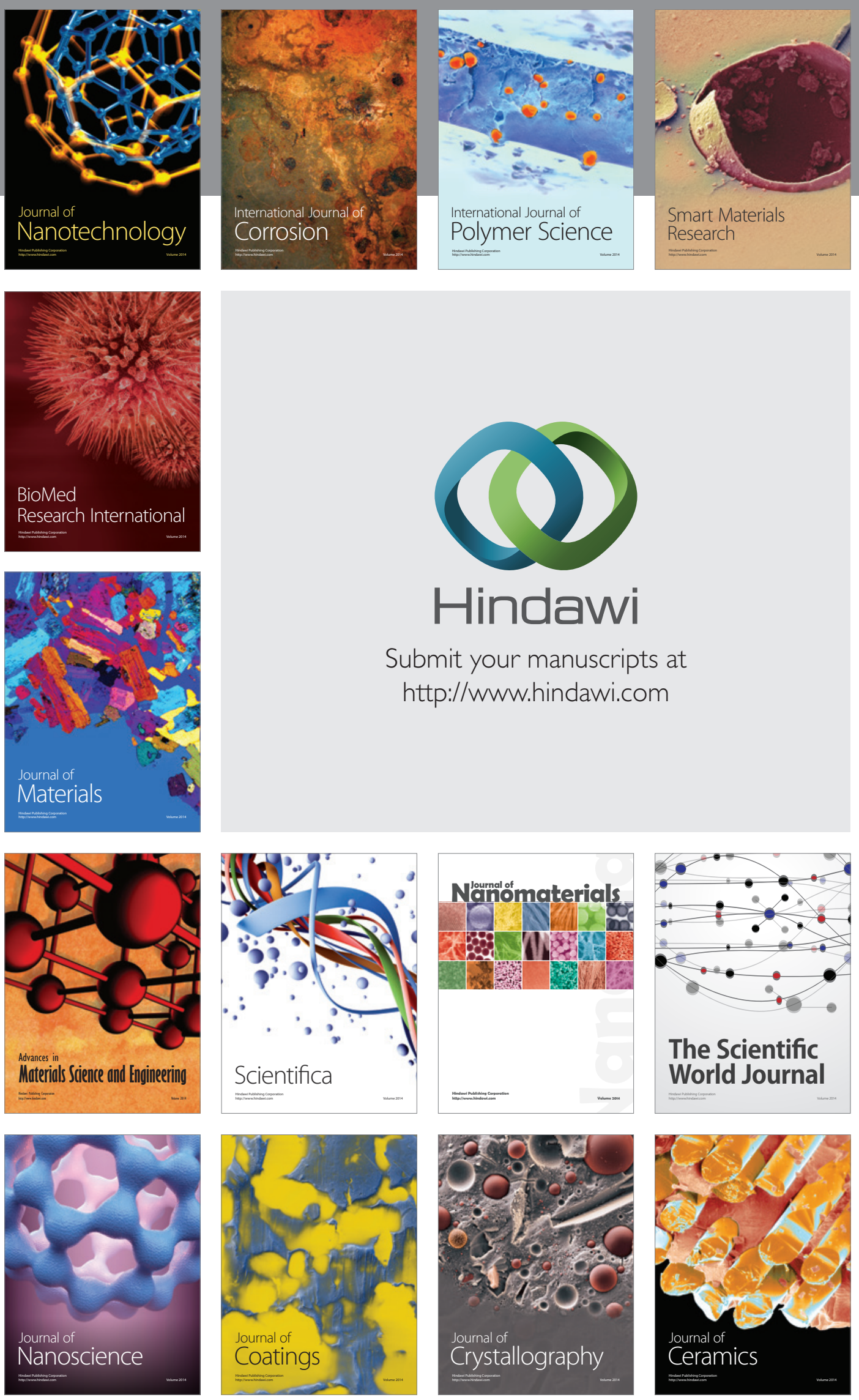

The Scientific World Journal

Submit your manuscripts at

http://www.hindawi.com

\section{World Journal}

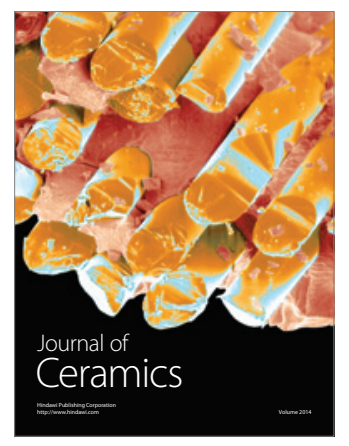

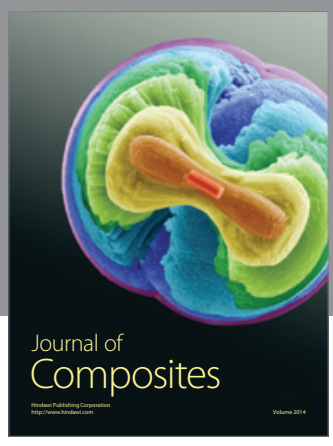
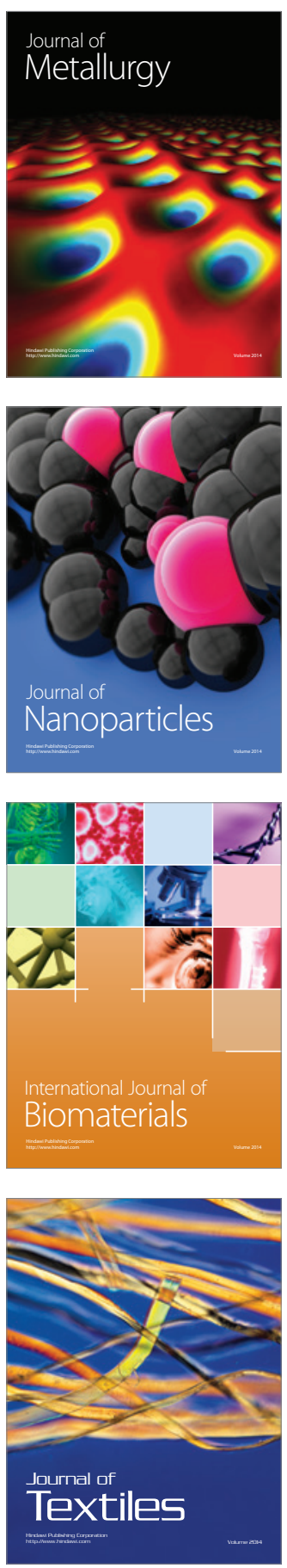